\title{
Penelitian BERBASIS AUDIOVISUAL TERHADAP PENGETAHUAN DAN SIKAP MAHASISWA TENTANG INTERPROFESSIONALEDUCATION (IPE) DI FKIK UIN ALAUDDIN MAKASSAR
}

\author{
Ayu Rahayu', Patima², Ani Auli IImi \\ Huriati $^{4}$ \\ Program Studi Keperawatan Fakultas \\ Kedokteran dan Ilmu Kesehatan Universitas \\ Islam Negeri Alauddin Makassar \\ Ayur3020@gmail.com
}

\begin{abstract}
ABSTRAK
Interprofesional Education (IPE) adalah salah satu konsep pendidikan terintegrasi untuk peningkatan kemampuan kolaborasi. IPE dapat terjadi ketika dua atau lebih mahasiswa dari program studi kesehatan yang berbeda belajar bersama yang bertujuan untuk meningkatkan kerja sama dan kualitas pelayanan kesehatan. Audio visual merupakan salah satu media penyampaian informasi yang menarik dan dapat merangsang lebih banyak indera. Tujuan dari penelitian ini untuk diketahuinya pengaruh pemberian informasi berbasis audio visual terhadap pengetahuan dan sikap mahasiswa tentang Interprofessional Education (IPE) di FKIK UIN Alauddin Makassar. Penelitian ini menggunakan desain penelitian Quasi Experiment Design dengan pendekatan Pre-test - Post-test with control group design. Jumlah sampel pada penelitian sebanyak 128 responden pre-test dan post-test dengan teknik pengambilan sampel menggunakan Purposive Sampling. Pada penelitian ini menggunakan2Kuesioneryaitukuesionerpengetahuansebanyak23pertanyaandankuesi onersikapsebanyak

15 pertanyaan. Analisa data menggunakan uji statistik Uji Wilcoxon Test. Hasil pengolahan data dengan menggunakan uji Wilcoxon Test jika $\mathrm{p}<0,05$ yang berarti bahwa $\mathrm{H}_{a}$ diterima dan $\mathrm{H}_{0}$ ditolak. Ada pengaruh yang bermakna antara pengetahuan dan sikap sebelum dan sesudah diberikan informasi berbasis audio visual. Pada kelompok intervensi didapatkan nilai $(p=0,000)$ atau $<0,05$ sedangkan pada kelompok kontrol pengetahuan $(p=0,013)$ dan sikap pada kelompok kontrol $(p=0,003)$ atau < 0,05 . Peneliti merekomendasikan penggunaan media audio visual dalam pemberian informasi upaya untuk meningkatan pengetahuan dan sikap mahasiswa.
\end{abstract}

Kata Kunci : Interprofessional Education (IPE), Pengetahuan dan Sikap 


\begin{abstract}
Interprofessional Education (IPE) connotes one of the concepts of integrated education to improve collaboration skills. IPE can occur when two or more students from differing health study programs learn together in purpose of enhancing collaboration and quality of health services. Audio- visual is one of intriguing media for delivering information that can stimulate more senses. The objective of the present study was to examine the effect of giving audio-visual based information on students' knowledge and attitudes of Interprofessional Education (IPE) in Faculty of Medicine and Health Science at UIN Alauddin Makassar. This study employed a quasi-experiment research design with the approach of pre-test - post-test with control group design. Purposely sampled, the number of samples involved in this study were 128 respondents in pre-test and post-test. In this investigation, 2 questionnaires namely knowledge questionnaire totaling 23 questions and attitude questionnaire totaling 15 questions were distributed. The data were analyzed using a statistical test Wilcoxon Test. The results of data processing using Wilcoxon Test revealed that $p<0.05$, which means that $H_{a}$ was accepted and $H_{0}$ was rejected. There was a substantial influence toward students' knowledge and attitude before and after giving the audio-visual based information. In intervention group, the obtained value was $(p=0,000)$ or $<0.05$, while in the control group, knowledge was valued $(p=0.013)$ and attitudes was valued $(p=0.003)$ or $<0.05$. The researcher recommends the use of audio-visual based media to addressing information in effort to enhance students' knowledge and attitudes.
\end{abstract}

\title{
Keywords: Interprofessional Education (IPE), Knowledge and Attitudes
}




\section{PENDAHULUAN}

Tuntutan pelayanan kesehatan yang berkualitas semakin meningkat seiring meningkatnya kesadaran masyarakat tentang kesehatan. Kunci dari pelayanan kesehatan yang bermutu dengan biaya yang efisien adalah dengan meningkatkan kolaborasi yang efektif antar tenaga kesehatan. Salah satu upaya untuk mewujudkan kolaborasi antar tenaga kesehatan adalah dengan memperkenalkan sejak dini paktik kolaborasi melalui proses pendidikan ${ }^{[20]}$.

Praktik kolaborasi sangat penting dalam dunia kesehatan. Banyaknya permasalahan pasien yang tidak dapat ditangani oleh satu profesi kesehatan, melainkan harus melibatkan berbagai profesi kesehatan guna memecahkan permasalahan pasien. Praktik kolaborasi bukan hanya untuk keselamatan pasien saja, akan tetapi untuk meningkatkan kepuasan pasien serta terciptanya mutu pelayanan kesehatan yang baik ${ }^{[17]}$. Model pelayanan kesehatan ini merupakan terobosan yang sedang dikembangkan untuk meningkatkan kualitas pelayanan kesehatan dan menghindari kesalahan praktek, dimana berbagai profesi bersama-sama menangani masalah pasien. Kemampuan bekerja sama dalam tim, komunikasi dan saling memahami tugas dan tanggung jawab antar profesi merupakan sebuah keharusan dimiliki oleh seluruh anggota tim pemberi pelayanan kesehatan ${ }^{[9]}$.

Permasalahan yang saat ini dihadapi oleh dunia pelayanan kesehatan di Indonesia adalah adanya gap antar profesi yang menyebabkan tidak terintegrasinya profesi-profesi pemberi pelayanan kesehatan dalam sebuah asuhan. Hal tersebut terjadi karena proses pembelajaran yang saat ini digunakan terfokus pada pencapaian kompetensi masing-masing profesi, kondisi ini menyebabkan terfragmentasinya profesi-profesi kesehatan dalam melakukan asuhan pelayanan terhadap pasien ${ }^{[9]}$. Pelayanan yang ada di Rumah Sakit merupakan pelayanan yang multidisiplin sehingga bisa berpotensi terjadinya pelayanan yang tumpah tindih, terjadinya konflik interprofessional dan juga keterlambatan dalam pemeriksaan dantindakan.
Dari permasalahan tersebut, salah satu upaya untuk mewujudkan kolaborasi antar tenaga kesehatan adalah dengan memperkenalkan praktik kolaborasi sejak dini melalui Interprofessional Education (IPE) adalah salah satu konsep pendidikan terintegrasi untuk meningkatkan kemampuan kolaborasi. IPE dapat terjadi ketika dua atau lebih mahasiswa dari program studi kesehatan yang berbeda-beda belajar bersama dengan tujuan untuk meningkatkan kerjasama dan kualitas pelayanan kesehatan. IPE memberikan kesempatan kepada mahasiswa yang mempunyai latar belakang yang bervariasi untuk bekerjasama secara aktif dalam memecahkan permasalahan. Pembelajaran ini, berpotensi untuk mempersiapkan mahasiswa menghadapi praktik klinik, membantu meningkatkan hubungan professional yang kuat dengan profesi kesehatan lainnya ${ }^{[14]}$.

Interprofessional Education (IPE) adalah metode yang ditawarkan oleh World Health Organization (2010) untuk mendukung kolaborasi dua profesi atau kesehatan atau lebih untuk menciptakan kerja tim yang ideal. Interprefessional Education adalah kegiatan pembelajaran yang di ikuti oleh dua profesi atau lebih yang belajar tentang dan dari satu sama lain untuk mewujudkan kolaborasi yang efektif dan efesien untuk meningkatkan kolaborasi secara efektif dan meningkatkan pelyanan kesehatan. Setelah mahasiswa memahami cara bekerja secara interprofesional, maka mereka akan siap untuk memasuki kerja sebagai anggota tim yang kolaboratif dan ini merupakan langkah untuk memindahkan sistem pendidikan kesehatan ke posisi yang lebih kuat.

Interprofessional education (IPE) adalah salah satu konsep pendidikan terintegrasi untuk peningkatan kemampuan kolaborasi. IPE dapat terjadi ketika dua atau lebih mahasiswa dari program studi kesehatan yang berbeda belajar bersama yang bertujuan untuk meningkatkan kerja sama dan kualitas pelayanan kesehatan. Kolaborasi interprofesi dapat dimulai pada masa perkuliahan, itulah yang dinamakan sebagai pendidikan interprofesi atau dikenal dengan IPE. IPE terjadi ketika dua atau lebih profesi kesehatan yang belajar bersama, belajar dari profesi kesehatan lain, dan mempelajarimasing-masing 
profesi kesehatan untuk meningkatkan kemampuan kolaborasi dan kualitas pelayanan kesehatan ${ }^{[5]}$.

Negara di dunia seperti Amerika Serikat, Norwegia, Swedia, dan Canada telah melakukan peneltian tentang Interprofessional Education di Universitas di negara tersebut misalnya saja di Amerika Serikat yaitu perkembangan Interprofesional Education di East Carolina University merupakan program pelatihan di Amerika Serikat yang terdiri dari tiga sampai empat jam sesi selama empat bulan. Pendidik belajar bagaimana kenyamanan siswa dengan interprofessional[19] .Menurut data DIKTI (2006) terdapat 12 Universitas Negeri di Indonesia yang menyelenggarakan pendidikan formal profesi kesehatan yang di dalamnya terdapat program pendidikan dokter dan pendidikan keperawatan. Menurut A'la (2012) Dengan adanya Universitas yang menyelenggarakan beberapa program pendidikan kesehatan. Hal ini yang menjadi salah satu kelebihan untuk mengembangkan konsep IPE di Indonesia. Sudah seharusnya isu mengenai IPE dikembangkan dan ditindak lanjuti dengan serius agar terciptanya kualitas mutu pelayanan kesehatan. Penerapan IPE di Indonesia sangat bermanfaat bagi calon sarjana kesehatan di Indonesia terutama untuk menciptakan adanya Interprofessional Collaboration ataupun Kolaborasi Interprofesi antar tenaga kesehatan yang berasal dari disiplin ilmu yang berbeda.

IPE yang telah didesain oleh WHO (World Health Organization), merupakan desain pembelajaran untuk pendidikan profesi kesehatan, di UIN Alauddin Makassar terdapat Fakultas Kedokteran dan IImu Kesehatan, yang memiliki lima program pendidikan profesi kesehatanyaitu; 1) Keperawatan, 2) Kebidanan, 3) Farmasi, 4) Kesehatan Masyarakat dan 5) Kedokteran, sehingga atas dasar tersebut IPE dapat menjadi sebuah pembelajaran yang dapat diterapkan, agar tercipta lulusan-lulusan yang siap berkolaborasi guna meningkatkan kualitas pelayanankesehatan.

Berdasarkan penelitian Susanti (2015) bahwa sebagian besar responden memiliki pengetahuan yang kurang tentang Interprofessional Education (IPE). Sebagianbesar responden memiliki kesiapan yang baik tentang Interprofessional Education (IPE).

\section{METODE PENELITIAN}

Penelitian merupakan metode penelitian Quasi Experiment Design dengan pendekatan Pre-test - Post-test with control group design. Pada penelitian ini terdapat dua kelompok yaitu kelompok kontrol dan kelompok intervensi. Sebelum diberikan informasi, pada kedua kelompok dilakukan pre-test (pengamatan awal), kemudian dilanjutkan dengan pemberian informasi kepada kelompok kontrol dan kelompok intervensi. Setelah itu, dilakukan kembali post-test (pengamatanakhir).

Populasi pada penelitian ini adalah seluruh mahasiswa Fakultas Kedokteran dan IImu Kesehatan UIN Alauddin Makassar sebanyak 1.677 orang. Untuk penetuan jumlah sampel menggunakan rumus penelitian Quasi Experiment diperoleh jumlah sampel sebanyak 64 responden masing- masing kelompok yaitu 64 orang kelompok kontrol dan 64 orang kelompok intervensi. Teknik pengambilan sampel menggunakan menggunakan Purposive Sampling yaitu suatu tehnik penetapan sampel dengan cara memilih sampel diantara populasi yang sesuai dan dikehendaki oleh peneliti, sehingga sampel tersebut dapat mewakili karakteristik populasi yang telah dikenalsebelumnya.

\section{HASIL PENELITIAN}

Penelitian ini dilaksanakan pada tanggal 1-8 Februari 2019. Dengan jumlah sampel sebanyak 128 orang yang terdiri 2 kelompok yaitu kelompok intervensi 64 orang dan kelompok kontrol 64 orang. Peneliti pertama-tama membagikan lembaran persetujuan (Inform consent) kepada responden sebagai bentuk persetujuan untuk menjadi responden dalam penelitian tersebut, selanjutnya peneliti membagikan kuesioner yang terbagi atas 2 macam yaitu yang pertama kuesioner pengetahuan tentang Interprofessional Education (IPE) yang terdiri dari 23 pertanyaan dan yang kedua kuesioner sikap tentang Interprofessional 
Education (IPE) yang terdiri dari 15 pertanyaan. Peneliti membagikan kuesioner pre-post kepada masing-masing kelompok, selanjutnya diberikan perlakuan untuk kedua anggota kelompok yaitu 2 kali dalam 1 pekan dan selanjutnya peneliti membagikan kuesioner post-test.

\section{Karakteristik mahasiswa FKIK UIN Alauddin Makassar}

Tabel 4.1

Distribusi Frekuensi dan

Persentase Berdasarkan

Karakteristik Data Demograsi Responden $(n=128)$

\begin{tabular}{|c|c|c|c|c|}
\hline \multirow{3}{*}{ Karakteristik } & \multicolumn{4}{|c|}{ Kelompok } \\
\hline & \multicolumn{2}{|c|}{ Intervensi } & \multicolumn{2}{|c|}{ Kontrol } \\
\hline & $\mathbf{n}$ & $(\%)$ & $\bar{n}$ & $(\%)$ \\
\hline \multicolumn{5}{|l|}{ Jenis Kelamin } \\
\hline Laki-laki & 12 & 18,8 & 10 & 15,6 \\
\hline Perempuan & 52 & 81,2 & 54 & 84,4 \\
\hline \multicolumn{5}{|l|}{ Usia } \\
\hline 19 tahun & 42 & 65,6 & 50 & 78,1 \\
\hline 20tahun & $\underline{22}$ & $\underline{34,4}$ & $\underline{14}$ & $\underline{28}$ \\
\hline \multicolumn{5}{|l|}{ Jurusan } \\
\hline Keperawatan & 16 & 25 & 16 & 25 \\
\hline Kesehatan & 16 & 25 & 16 & 25 \\
\hline \multicolumn{5}{|l|}{ Masyarakat } \\
\hline Kebidanan & 16 & 25 & 16 & 25 \\
\hline Farmasi & 16 & 25 & 16 & \\
\hline \multicolumn{5}{|l|}{ Suku } \\
\hline Makassar & 28 & 43,8 & 34 & 53,1 \\
\hline Bugis & 36 & $\underline{56,6}$ & $\underline{30}$ & $\underline{46}$ \\
\hline Total & 64 & 100 & 64 & 10 \\
\hline
\end{tabular}

Sumber : Data Primer, 2019

Berdasarkan tabel 4.1 didapatkan bahwa jenis kelamin responden di dominasi oleh perempuan dibandingkan laki-laki sedangkan usia responden paling banyak di dominasi oleh usia 19 tahun. Pada karakteristik responden berdasarkan jurusan bahwa empat jurusan memiliki responden yang sama banyak yaitu 32 responden (25\%) untuk kelompok kontrol dan kelompok intervensi. Selanjutnya adalah suku responden yang didominasi adalah suku bugis sebanyak 66 responden kelompok intervensi dankelompok kontrol.

\section{Analisis Univariat}

Tabel 4.2

Distribusi Frekuensi Pengetahun Pre-Test dan Post-Test Mahasiswa Kelompok Intervensi dan Kelompok Kontrol Tentang Interprofessional Education (IPE) di FKIK UIN Alauddin Makassar $(n=128)$

\begin{tabular}{|c|c|c|c|c|c|c|c|c|}
\hline & & & $\begin{array}{l}\text { Kelo } \\
\text { Inte }\end{array}$ & $\begin{array}{l}\text { npok } \\
\text { vensi }\end{array}$ & & Colom & ok & ntrol \\
\hline & Pre- & & & $t$-test & & -test & & t-test \\
\hline & $\mathrm{n}$ & $\%$ & $\mathrm{n}$ & $\%$ & $\mathrm{n}$ & $\%$ & $\mathrm{n}$ & $\%$ \\
\hline Baik & 3 & 4,7 & 43 & 67,2 & 3 & 4,7 & 9 & 14,1 \\
\hline Cukup & 20 & 31,2 & 19 & 29,7 & 37 & 57,8 & 39 & 60,9 \\
\hline Kurang & 41 & 64,1 & 2 & 3,1 & 24 & 37,5 & 16 & 25,0 \\
\hline Total & 64 & 100 & 64 & 100 & 64 & 100 & 64 & $\underline{100}$ \\
\hline
\end{tabular}

Pada tabel 4.2 menunujukan bahwa pretest kategori baik sebanyak 3 responden $(4,7 \%)$ dan setelah diberikan intervensi informasi berbasis audiovisual sehingga post-test menjadi 43 responden $(67,2 \%)$. Sedangkan pada kategori pengetahuan kurang baik pre-test sebanyak 41 responden $(64,1 \%)$ dan setelah diberikan intervensi sehingga post-test menjadi 2 responden $(3,1 \%)$. Sedangkan pengetahuan kelompok kontrol menunjukan bahwa pre-test kategori baik sebanyak 3 responden $(4,7 \%)$ dan setelah diberikan informasi berupa booklet sehingga posttest menjadi 9 responden $(14,1 \%)$ dan pengetahuan kategori kurang baik pre-test sebanyak 24 responden $(37,5 \%)$ dan setelah diberikan informasi berupa booklet sehingga posttest 16 responden(25\%).

\section{Tabel 4.3}

Distribusi Frekuensi Sikap Pre-Test dan

Post- Test Mahasiswa Kelompok Intervensi dan Kelompok Kontrol tentang

Interprofessional Education (IPE) di FKIK UIN Alauddin Makassar $(n=128)$

\begin{tabular}{rcccccccc}
\hline & \multicolumn{3}{c}{ Kelompo } & \multicolumn{2}{c}{ Kelompok Kontrol } \\
k & \multicolumn{4}{c}{ Intervensi } \\
Kateg & \multicolumn{3}{c}{ o ri } & Pre-test & \multicolumn{1}{c}{ Post-test } & Pre-test & \multicolumn{2}{c}{ Post-test } \\
\cline { 2 - 9 } & $\mathbf{n}$ & $\%$ & $\mathbf{n}$ & $\%$ & $\mathbf{n}$ & $\%$ & $\mathbf{n}$ & $\%$ \\
\hline Baik & 18 & 28,1 & 33 & 51,6 & 27 & 42,2 & 36 & 56,3
\end{tabular}




\begin{tabular}{lcccccccc}
\hline Kurang & 46 & 71,9 & 31 & 48,8 & 37 & 57,8 & 28 & 43,7 \\
\hline Total & $\mathbf{6 4}$ & $\mathbf{1 0 0}$ & $\mathbf{6 4}$ & $\mathbf{1 0 0}$ & $\mathbf{6 4}$ & $\mathbf{1 0 0}$ & $\mathbf{6 4}$ & $\mathbf{1 0 0}$
\end{tabular}

Sumber : Data primer, 2019

Berdasarkan tabel 4.3 bahwa sikap mahasiswa kelompok intervensi menunjukan bahwa pre-test kategori baik sebanyak 18 responden $(28,1 \%)$ dan setelah diberikan intervensi informasi berbasis audiovisual post-test menjadi 33 responden $(51,6 \%)$, sedangkan pada kategori kurang baik pre-test sebanyak 46 responden $(71,9 \%)$ dan post-test 31 responden $(48,4 \%)$. Sedangkan sikap mahasiswa kelompok kontrol menunjukan bahwa sikap mahasiswa kelompok kontrol pre-test kategori baik sebanyak 27 responden $(42,2 \%)$ dan setelah diberi informasi tentang IPE berupa booklet sehinggapost-test

menjadi 36 responden (56,3\%)sedangkansikap mahasiswapre-testkategorikurangbaik37

responden $(57,8 \%)$ dan post-test sebanyak28 responden $(43,7 \%)$.

\section{Analisis Bivariat}

\section{Tabel 4.4}

\section{Pengaruh Pemberian Informasi \\ Berbasis Audio Visual Terhadap \\ Pengetahuan Mahasiswa Tentang \\ Interprofessional Education (IPE) di \\ FKIK UIN Alauddin Makassar $(n=128)$}

\begin{tabular}{|c|c|c|c|c|}
\hline Kategori & Baik & Cukup & Kurang & $P$-Value \\
\hline $\begin{array}{l}\text { Pengetahuan } \\
\text { Kelompok } \\
\text { Intervensi }\end{array}$ & & & & \\
\hline Pre-test & 3 & 20 & 41 & 0,000 \\
\hline Post-test & 43 & 19 & 2 & \\
\hline $\begin{array}{l}\text { Pengetahuan } \\
\text { Kelompok } \\
\text { Kontrol }\end{array}$ & & & & \\
\hline $\begin{array}{c}\text { Pre-test } \\
\text { Post-test }\end{array}$ & $\begin{array}{l}3 \\
9\end{array}$ & $\begin{array}{l}37 \\
39\end{array}$ & $\begin{array}{l}24 \\
16\end{array}$ & 0,013 \\
\hline
\end{tabular}

Sumber : Data primer, 2019

Berdasarkan tabel 4.4 menunjukan bahwa kelompok interevnsi didapatkan hasil bahwa analisis statistic dengan menggunakan uji Wilcoxon didapatkan nilai signifikan $\mathrm{P}$-Value sebesar 0,000. Jika nilai signifikan $p<0,05$, maka dapat disimpulkan bahwa ada pengaruh yang sangat bermakna terhadap pemberian informasi berbasis audio visual terhadap pengetahuan. Sedangkan pengetahuan kelompok kontrol menunjukan bahwa hasil analisis statistic dengan menggunakan uji Wilcoxon didapatkan nilai $p$ value 0,013 . Jika nilai $P<0,05$, sehingga dapat disimpulkan bahwa ada pengaruh pemberian booklet terhadap pengetahuan mahasiswa tentang Interpofessional Education (IPE).

Tabel 4.5

\section{Pengaruh Pemberian Informasi Berbasis Audio Visual pre-test dan post-test Terhadap Sikap Mahasiswa Tentang Interprofessional Education (IPE) di FKIK UIN Alauddin Makassar $(n=128)$}

\begin{tabular}{|c|c|c|c|}
\hline Kategori & Baik & Kurang & $\underline{P \text {-Value }}$ \\
\hline Sikap Kelompok & & & \\
\hline Intervensi & 18 & 46 & 0,000 \\
\hline Pre-test & 33 & 31 & \\
\hline Post-test & & & \\
\hline Sikap Kelompok & & & \\
\hline Kontrol & 27 & 37 & 0,003 \\
\hline Pre-test & 36 & 28 & \\
\hline
\end{tabular}

Post-test

Sumber : Data primer, 2019

Berdasarkan tabel 4.5 kelompok intervensi menunjukan bahwa hasil analisis statistic menggunakan uji Wilcoxon didapatkan hasil $p$ value 0,000 . Jika nilai signifikan $P<0,05$ maka dapat disimpulkan bahwa ada pengaruh yang bermakna pemberian informasi berbasis audio visual terhadap sikap mahasiswa tentang Interprofessional Education (IPE) di FKIK UIN Alauddin Makassar. Sedangkan Sikap kelompok kontrol menunjukan hasil uji analisis statistic menggunakan uji Wilcoxon didapatkan hasil nilai $\mathrm{P}$-value $=0,003$. Jika nilai signifikan $\mathrm{P}<0,05$ maka dapat disimpulkan bahwa ada pengaruh pemberian informasi menggunakan media booklet terhadap sikap mahasiswa tentang Interprofessional Education (IPE) di FKIK UIN AlauddinMakassar. 
Tabel 4.6

Perbedaan Pengaruh Pemberian Informasi Kelompok Intervensi dan Kelompok Kontrol Terhadap Pengetahuan dan Sikap Mahasiswa tentang Interprofessional Education (IPE) di FKIK UIN Alauddin Makassar (Uji Wilcoxon)

\begin{tabular}{|c|c|c|}
\hline Variabel & $\begin{array}{l}\text { Kelompok } \\
-\quad \frac{\text { Intervensi }}{P-\text { Value }}\end{array}$ & $\begin{array}{c}\text { Kelompok } \\
\text { Kontrol } \\
P \text {-Value }\end{array}$ \\
\hline $\begin{array}{l}\text { Pengetahuan } \\
\text { Pre-test } \\
\text { Post-test }\end{array}$ & 0,000 & 0,013 \\
\hline $\begin{array}{c}\text { Sikap } \\
\text { Pre-test } \\
\text { Post-test } \\
\end{array}$ & 0,000 & 0,003 \\
\hline
\end{tabular}

Sumber : Data primer, 2019

Berdasarkan tabel 4.6 menunjukan hasil uji statistic menggunakan Uji Wilcoxon didapatkan nilai $p$ value pada pengetahuan kelompok intervensi adalah sebesar 0,000 . Jika nilai signifikan $\mathrm{P}<0,005$ sehingga dapat disimpulkan bahwa terdapat pengaruh yang bermakna pemberian informasi berbasis audio visual terhadap pengetahuan sedangkan untuk kelompok kontrol didapatkan nilaip value sebesar 0,013. Jika nilai $P<0,05$ maka dapat disimpulkan bahwa terdapat pengaruh pemberian informasi berupa booklet terhadap pengetahuan mahasiswa tentang Interprofessional Education. Jadi, pangaruh pemberian informasi antara kelompok intervensi dan kelompok kontrol sama-sama berpengaruh akan tetapi kelompok intervensi memiliki pengaruh yang lebih bermakna dibandingkan dengan kelompok kontrol. Sedangkan untuk sikap kelompok intervensi didapatkan nilai $p$ value sebesar 0,000 dan kelompok kontrol sebesar 0,003 . Jika nilai signifikan $\mathrm{P}<0,05$ maka dapat disimpulkan bahwa kelompok intervensi dan kelompok kontrol sama-sama berpengaruh, akan tetapi sikap kelompok intervensi lebih bermakna dibandingkan dengan kelompokkontrol.

\section{Pembahasan}

\section{Karakteristik}

responden

Berdasarkan hasil penelitian menunjukan bahwa jenis kelamin responden didominasi perempuan karena yaitu sebanyak 52 responden $(81,2 \%)$ untuk kelompok intrervensi dan kelompok kontrol sebanyak 54 responden $(84,4 \%)$ karena realita yang dapat kita sekarang adalah tenaga kesehatan di dominasi perempuan. Hasil penelitian ini sejalan dengan penelitian yang dilakukan oleh Suryandari, G dkk (2015) dengan judul "Kesiapan Mahasiswa Dalam Pelaksanaan Pendidikan Interprofesional di Fakultas Kedokteran dan IImu Kesehatan Muhamadiyah Yogyakarta" Penelitian analitik pada kesiapan siswa dalam pelaksanaan pendidikan interprofesional di Fakultas Kedokteran Dan IImu Kesehatan Muhamadiyah Yogyakarta. Hasil penelitian menyatakan bahwa sebagian besar mahasiswa adalah berjenis kelamin perempuan. Penelitian ini juga sejalan dengan (Sulastri, 2017) bahwa responden di dominasi perempuan sebanyak 124orang.

Hasil penelitian menunjukkan bahwa sebagian besar responden didominasi oleh mahasiswa yang berusia 19 tahun yaitu sebanyak 42 responden $(65,6 \%)$ untuk kelompok intervensi dan 50 responden $(78,1 \%)$ untuk kelompok kontrol karena responden dalam penelitian ini adalah mahasiswa semester 3 (angkatan 2017) yang rata-rata berusia 19 tahun. Notoatmodjo (2010) menyatakan bahwa umur seseorang berkaitan erat dengan pengetahuan. Usia semakin cukup umur seseorang, tingkat pengetahuannya akan lebih matang dalam berfikir dan bertindak. Hasil penelitian ini sejalan dengan penelitian yang dilakukan oleh Martina (2013) dengan judul hubungan efikasi diri dengan kesiapan terhadap interprofessional education (IPE) pada mahasiswa profesi di FK UGM. Hasil penelitian menyatakan bahwa sebagain besar responden memiliki usia $<20$ tahun. 


\section{Pengetahuan Mahasiswa Tentang Interprofessional Education (IPE) di FKIK UIN AlauddinMakassar}

Hasil penelitian menunjukan bahwa kelompok intervensi didapatkan peningkatan pengetahuan yang signifikan setelah diberikan informasi melalui audiovisual dimana pre-test kategori baik sebanyak 3 responden $(4,7 \%)$ dan post-test setelah diberikan informasi berabsis audiovisual menjadi 43 responden (67,2\%). Untuk kategori cukup baik menunjukan bahwa pre-test sebanyak 20 responden $(31,2 \%)$ dan pada postest menjadi 19 responden (29,7\%). sedangkan pada kategori pengetahuan kurang baik pre-test sebanyak 41 responden $(64,1 \%)$ dan post-test setelah diberikan informasi berbasis audiovisual pengetahuan kategori kurang baik menjadi 2 responden $(3,1 \%)$. Jadi, dapat disimpulkan bahwa pemberian informasi berbasis audiovisual dapat meningkatkan pengetahuan mahasiswa tentang Interprofessional Education(IPE).

Berdasarkan hasil analisis yang telah dilakukan oleh peneliti, maka didapatkan hasil bahwa responden lebih banyak yang belum mengetahui tentang IPE dibandingkan dengan yang sudah mengetahui, hal ini berarti masih banyak responden yang sebelumnya belum mengetahui tentang IPE dan tidak pernah mendapatkan informasi tentang IPE baik dari media cetak, sosial media dan informasi lainnya.

Hal ini sesuai dengan teori ${ }^{[11]} y a n g$ menyatakan bahwa pemberian informasi adalah makna yang dapat diartikan sebagai pemberitahuan atau ilmu kepada seseorang. Adanya pemberian infromasi mengenai suatu hal akan memberikan landasan kognitif dan pengetahuan baru yang cukup bagi responden serta meningkatkan pengetahuan responden. Hal ini juga sejalan dengan pendapat peneliti karena lebih banyak responden yang tidak pernah mendapatkan infromasi tentang IPE sehingga akan mempengaruhi pengetahuan Mahasiswa. Hasil penelitian menujukkan bahwa hanya sedikit responden yang memiliki pengetahuan baik karena banyak yang tidak pernah mendapatkan infromasi tentang IPESebelumnya.
Hal ini sejalan dengan penelitian yang dilakukan [2] "Efektifitas Promosi Kesehatan Melalui Audio Visual Dan Leaflet Tentang Sadari (Pemeriksaan Payudara Sendiri) Terhadap Peningkatan Pengetahuan Remaja Putri Tentang Sadari di Sman 1 Kampar Tahun 2018" didapatkan bahwa sebelum diberikan video pengetahuan terdapat $(7,89 \%)$ dan setelah diberikan video terjadi peningkatan menjadi $(11,33 \%)$.

Berdasarkan hasil penelitian pada
kelompok kontrol menunjukan bahwa pengetahuan kelompok kontrol pre-test kategori baik sebanyak 3 responden $(4,7 \%)$ dan setelah diberikan informasi dengan media booklet posttest meningkat menjadi 9 responden $(14,1 \%)$ sedangkan kategori cukup baik pada pre-test sebanyak 37 responden $(57,8 \%)$ danposttest

menjadi 39 responden $(60,9 \%)$ dan pengetahuan kategori kurang baik pre-test sebanyak 24 responden $(37,5 \%)$ dan post-test 16 responden (25\%).

Hasil penelitian ini sejalan dengan penelitian yang dilakukan oleh Nur'aini (2016) "Pengaruh Pendidikan Kesehatan dengan Booklet Terhadap Pengetahuan dan Sikap Menstrual Hygiene Pada Siswi Di SDI Al-Falah I Jakarta" didapatkan hasil bahwa saat pre-test 7,33 dan setelah diberikan intervensi booklet sehingga terjadi peningkatan pengetahuan menjadi 11,87. Sejalan juga dengan penelitian yang dilakukan oleh dilakukan oleh Puspitaningrum, dkk (2017) yang berjudul "Pengaruh Media Booklet Terhadap Pengetahuan dan Sikap Remaja Putri Terkait Kebersihan dalam Menstruasi Di Pondok Pesantren Al-Ishlah Demak Triwulan II Tahun 2017" Hasil penelitian menunjukkan adanya perbedaan Hasil penelitian menunjukkan adanya perbedaan rata-rata skor pengetahuan kebersihan dalam menstruasi remaja putri pre-test dan posttest pemberian booklet dengan ratarata pretest 8,29 dan rata-rata posttest10,64.

Menurut Notoatmodjo (2010), bahwa semakin banyak informasi yang didapat maka akan mempengaruhi atau menambah pengetahuan bagi seseorang. Dengan pengetahuan dapat menimbulkan kesadaran seseorang dan akhirnya akan bersikap sesuai dengan pengetahuan yang dimiliki. 


\section{Sikap Mahasiswa Tentang Interprofessional Education (IPE) di FKIK UIN Alauddin Makassar}

Hasil penelitian menunjukan bahwa kelompok intervensi didapatkan sikap mahasiswa kelompok intervensi (pre-test) kategori baik sebanyak 18 responden (28,1\%) dan setelah diberikan informasi berabasis audiovisual sehingga post-test meningkat menjadi 33 responden $(51,6 \%)$, sedangkan pada kategori kurang baik pre-test sebanyak 46 responden (71,9\%) dan post-test 31 responden(48,4\%).

Penelitian ini sejalan dengan penelitian yang dilakukan oleh[6] dengan judul " Pengaruh Edukasi melalui Media Audio Visual terhadap Pengetahuan dan Sikap Remaja Overweight" didapatkan hasil bahwa sebelum diberikan edukasi melalui Media Audio Visual rata-rata sikap pre-test 36,45 dan post-test meningkatkan menjadi 39,65.

Penelitian ini menunjukan bahwa sikap mahasiswa kelompok kontrol pre-test kategori baik sebanyak 27 responden $(42,2 \%)$ dan posttest menjadi 36 responden (56,3\%) sedangkan sikap mahasiswa pre-test kategori kurang baik 37 responden $(57,8 \%)$ dan post-test sebanyak 28 responden $(43,7 \%)$.

Berdasarkan analisis yang telah dilakukan peneliti bahwa media booklet dapat mempengaruhi sikap seseorang karena dengan adanya pengetahuan yang dimiliki seseorang maka sikap dapat berubah. Peran booklet untuk mempengaruhi sikap berawal dari adanya pengetahuan responden yang membaca informasi melalui mediabooklet.

Peningkatan sikap dikarenakan oleh peningkatan pengetahuan. Peningkatan pengetahuan dan sikap diperoleh dari proses belajar dengan memanfaatkan semua alat indera yaitu $13 \%$ dari pengetahuan diperoleh dengan indera pendengaran dan 35-55\% melalui ndera penglihatan ${ }^{[8]}$. Menurut peneliti bahwa, hal ini sesuai dengan pemberian informasi melalui media booklet yaitu dapat menghasilkan peningkatan pengetahuan yang akan mempengaruhi perubahan sikap terhadap responden.

Menurut ${ }^{[18]}$ menyatakan bahwa sikap merupakan evaluasi yang dibuat manusia terhadap dirinya, orang lain maupun objek. Hal ini terjadi karena teori mengungkapkan bahwa sikap merupakan penentu yang dapat memunculkan perilaku sesuai dengan sikapnya. Jadi, sikap itu adalah sesuatu yang dipersepsikan dari pengetahuan.

\section{Pengaruh Pemberian informasi berbasis Audio Visual Terhadap Pengetahuan dan Sikap Mahasiswa Tentang Interprofessional Education (IPE) di FKIK UIN Alauddin Makassar}

Hasil analisis data kelompok intervensi menunjukkan bahwa terdapat pengaruh yang signifikan pemberian informasi berbasis audiovisual terhadap pengetahuan mahasiswa tentang Interprofesional Education (IPE) pada mahasiswa Fakultas Kedokteran dan IImu kesehatan (FKIK) UIN Alauddin Makassar pada kelompok intervensi dengan nilai $(p=0,000)$ atau $p<0.05$. Hal ini menunjukkan bahwa terdapat pengaruh yang bermakna pemberian informasi berbasis audiovisual terhadap pengetahuan mahasiswa tentang Interprofessional Education (IPE) di FKIK UIN Alauddin Makassar.

Berdasarkan analisis peneliti, pemberian informasi dengan video efektif dalam meningkatkan pengetahuan mahasiswa dimana seorang mahasiswa dapat menerima pesan dengan cepat dan mudah diingat dapat diterima dengan baik, lebih menarik dan tidak menonton karena mahasiswa mendengar dan melihat sehingga remaja sangat antusias terhadap isi video dan melihat video sampai selesai. melalui video mahasiswa akan dipaparkan secara jelas mengenai IPE.

Hal ini dukung oleh penelitian Depkes (2010) yang mengatakan bahwa pemilihan dan penggunaan alat bantu media video merupakan salah satu komponen yang penting dilakukan, dengan tujuan akan membantu penggunaan indera sebanyak-banyaknya. Seseorang mendapat pengetahuan melalui panca inderanya, karena sebagian besar diperoleh dari indera penglihatan (mata) yaitu sebesar $83 \%$, indera pendengaran (telinga) yaitu sebesar $11 \%$ sedangkan sisanya melalui indera perasa $1 \%$, indera peraba $2 \%$ dan yang terakhir indera penciuman sebanyak $3 \%$. 
Sejalan dengan penelitian yang dilakukan oleh Putri, dkk (2017) yang berjudul "Efektifitas Media Audio Visual Dan Leaflet Terhadap Peningkatan Pengetahuan, Sikap dan Tindakan Tentang Pencegahan Penyakit Gastritis Pada Santriwati Di Pondok Pesantren Hidayatullah Putri Dan Ummusshabri Kota Kendari Tahun 2017" bahwa ada pengaruh peningkatan pengetahuan yang signifikan $P=0,000$ atau $p<0,05$. Selaras dengan penelitian yang dilakukan oleh Zakaria \& Hanny Rono (2017) dengan judul "Pengaruh Pendidikan Kesehatan Dengan Media Audiovisual Terhadap Pengetahuan dan Sikap lbu Tentang Inisiasi Menyusu Dini Di Kota Yogyakarta" dengan hasil nilai signifikan $\mathrm{P}=0,000$ atau $\mathrm{p}<0,05$ dengan kata lain bahwa ada pengaruh yang signifikan pendidikan kesehatan dengan media Audiovisual terhadap pengetahuan. Sejalan juga dengan penelitian yang dilakukan oleh (Alini \& Indrawati, 2018) yang berjudul " Efektifitas Promosi Kesehatan Melalui Audio Visual Dan Leaflet Tentang Sadari (Pemeriksaan Payudara Sendiri) Terhadap Peningkatan Pengetahuan Remaja Putri Tentang Sadari Di Sman 1 Kampar Tahun 2018" hasil penelitian didapatkan bahwa ada pengaruh promosi kesehatan terhadap pengetahuan melalui audio visual dengan nilai $(p=0,003)$ atau $p<0,05$.

Adapun hasil analisis data kelompok kontrol menggunakan booklet didapatkan nilai signifikan $(p=0,013)$ atau $p<0,05$ artinya ada pengaruh pemberian informasi menggunakan booklet terhadap pengetahuan mahasiswa tentang Interprofessional Education (IPE) di FKIK UIN Alauddin Makassar. Selaras dengan penelitian yang dilakukan oleh Nur'aini (2016) "Pengaruh Pendidikan Kesehatan dengan Booklet Terhadap Pengetahuan dan Sikap Menstrual Hygiene Pada Siswi Di SDI Al-Falah I Jakarta" hasil uji statistic menunjukan terdapat pengaruh booklet terhadap pengetahuan pada siswi dengan nilai $(p=0,001)$ atau $p<0,05$. Sejalan dengan penelitian yang dilakukan oleh Ma'munah (2015) yang berjudul "Pengaruh Pendidikan Kesehatan dengan Booklet Terhadap Pengetahuan Ibu Laktasi di Wilayah Kerja Puskesmas Ciputat Timur" pada perhitungan statistic menunjukan hasil bahwa ada pengaruh pendidikan kesehatan dengan Booklet terhadap pengetahuan ibu laktasi dengan nilai $(p=0,001)$ ataup $<0,05$. Jadidapatdisimpulkan bahwa ada pengaruh pendidikan kesehatan yang disampaikan dengan media Booklet terhadap pengetahuan ibu laktasi. Selanjutnya sejalan juga dengan penelitian yang dilakukan oleh (Mursida \& Anastasia Suci, 2016) "Pengaruh Media Booklet Terhadap Pengetahuan Dan Sikap Tentang Perilaku Hidup Bersih Dan Sehat (PHBS) Pada Siswa Di SMP Negeri I Palibelo" berdasarkan analisis uji Wilcoxon menunjukan taraf signifikan nilai $p=0,000$ atau $p<0,05$ artinya ada pengaruh yang signifikan dari pendidikan kesehatan dengan media booklet terhadap pengetahuan tentang perilaku hidup bersih dan sehat (PHBS). Penelitian ini juga selaras dengan penelitian yang dilakukan oleh (Pratiwi, 2017) yang berjudul "Efektifitas Pemberian Booklet Terhadap Tingkat Pengetahuan Dan Sikap Terhadap Pencegahan HIV dan AIDS pada Remaja Siswa Kelas VIII di SMPN 1 Cangkringan Sleman" Didapatkan hasil bahwa sikap pencegahan dengan nilai $p$ sebesar 0,004 . Berdasarkan nilai signifikasi ( $p$ ) dimana $p<0,05$, hasil tersebut menunjukkan terdapat pengaruh yang signifikan terhadap pengetahuan pencegahan setelah diberikan media booklet. Jadi, Pemberian booklet efektif terhadap tingkat pengetahuan pencegahan HIV dan AIDS pada remaja siswa SMP kelas VIII di SMPN 1 Cangkringan,Sleman.

Menurut Notoatmodjo (2010) bahwa seseorang yang berperilaku itu sebelumnya ia harus terlebih dahulu tahu apa arti atau manfaat perilaku tersebut bagi dirinya ataupun orng lain. Pengetahuan adalah hasil dari tau, dan ini terjadi setelah orang melakukan penginderaan terhadap suatu objek tertentu. Pengetahuan atau kognitif merupakan domain yang sangat penting untuk membentuk tindakan seseorang.

\section{Analisis perbedaan Pengaruh Pemberian Informasi Kelompok Intervensi dan Kelompok Kontrol Terhadap Pengetahuan dan Sikap Mahasiswa Tentang Interprofessional Education (IPE) di FKIK UIN Alauddin Makassar.}

Pemberain informasi berbasis audiovisual untuk kelompok intervensi dan pemberian informasi menggunakan media booklet samasama berpengaruh, akan tetapi Berdasarkan hasil uji statistic menggunakan Uji Wilcoxon didapatkan 
nilai $\mathrm{p}$ value pada pengetahuan kelompok intervensi yang diberikan perlakuan pemberian informasi menggunakan audiovisual adalah sebesar $P=0,000$. Jika nilai signifikan $P<0,005$ sehingga dapat disimpulkan bahwa terdapat pengaruh yang bermakna pemberian informasi berbasis audio visual terhadap pengetahuan sedangkan untuk kelompok kontrol didapatkan nilai $p$-value sebesar 0,013 . Jika nilai $P<0,05$ maka dapat disimpulkan bahwa terdapat pengaruh pemberian informasi menggunakan media booklet terhadap pengetahuan mahasiswa tentang Interprofessional Education. Jadi, pangaruh pemberian informasi antara kelompok intervensi dan kelompok kontrol sama-sama berpengaruh akan tetapi kelompok intervensi memiliki pengaruh yang lebih bermakna dibandingkan dengan kelompok kontrol. Sedangkan untuk sikap kelompok intervensi didapatkan nilai $p$-value sebesar 0,000 dan kelompok kontrol sebesar 0,003. Jika nilai signifikan $\mathrm{P}<0,05$ maka dapat disimpulkan bahwa kelompok intervensi dan kelompok kontrol sama-sama berpengaruh, akan tetapi sikap kelompok intervensi lebih bermakna dibandingkan dengan kelompokkontrol.

\section{KESIMPULAN}

1. Hasil penelitian berdasarkan karaketristik responden jenis kelamin perempuan lebih dominan dibandingkan laki-laki. Umur responden mayoritas 19 tahun. Responden dari 4 jurusan sama banyak dan suku lebih banyak bugis dari padamakassar.

2. Hasil penelitian pre-test dan post-test pemberian informasi berbasis audiovisual terjadi perubahan yang signifikan sebelum dilakukan pemberian informasi berbasis audiovisual menunujukan bahwa pre-test kategori baik sebanyak 3 responden $(4,7 \%)$ dan post-test meningkatkan menjadi 43 responden (67,2\%). Untuk kategori cukup baik menunjukan bahwa pre-test sebanyak 20 responden $(31,2 \%)$ dan pada pos-test menjadi 19 responden (29,7\%) sedangkan pada kategori pengetahuan kurang baik pretest sebanyak 41 responden $(64,1 \%)$ dan post-test sebanyak 2 responden(3,1\%).

3. Hasil penelitian sikap menunjukan bahwa sikap mahasiswa sebelum diberikan intervensi terjadi perubahan yangccukup signifikan yaitu pre-test kategori baik sebanyak 18 responden $(28,1 \%)$ danposttest

meningkat menjadi 33 responden $(51,6 \%)$, sedangkan pada kategori kurang baik pretest sebanyak 46 responden $(71,9 \%)$ danpost-test

31 responden $(48,4 \%)$.

4. Hasil uji Wilcoxon menunjukan bahwa ada perubahan yang bermakna antara pengetahuan dan sikap mahasiswa tentang Interprofessional Education (IPE) pre-test dan post-test pemberian informasi berbasis audiovisual, pada kelompok intervensi didapatkan nilai signifkan $(p=0,000)$ atau $p<$ 0,05

5. Ada perbedaan yang bermakna antara kelompok intervensi dan kelompok kotrol pemberian informasi berbasis audiovisual.

\section{SARAN}

1. Bagilntitusi

Hasil Penelitian ini menjadi salah satu pertimbangan bagi pihak pemegang kebijakan di FKIK UIN Alauddin Makassar agar segera diterapkan IPE upaya untuk meningkatkan mutu pelayanan kesehatan dan dapat menghasilkan lulusan yang berkualitas dan mampu berkolaborasi dengan baik antara tenagakesehatan.

2. Bagi peneliti

Penelitian diharapkan dapat memberikan pengalaman kepada penulis dan menambah wawasan tentang tentang Interprofessional Education (IPE).

3. Bagi masyarakat

Penelitian ini dapat menjadi informasi baru bagi masyarakat tentang adanya model pembelajaran IPE yang dapat bermanfaat untuk peningkatan kualitas pelayanan kesehatan 


\section{DAFTAR PUSTAKA}

1. A'la, M. Z.,. Persepsi Dan Kesipan Mahasiswa Tahap Akademik Di Fakultas Kedokteran Universitas Gajah Mada. Journal Of Health Science, 184-197. 2012

2. Alini, \& Indrawati. Efektifitas Promosi Kesehatan Melalui Audio Visual Dan Leaflet Tentang Sadari (Pemeriksaan Payudara Sendiri) Terhadap Peningkatan Pengetahuan Remaja Putri Tentang Sadari Di Sman 1 Kampar Tahun 2018. Jurnal Ners Volume 2 Nomor 2, 1-9.2018

3. Depkes RI. Keputusan Menteri Kesehatan Republik Indonesia No. Hk. 03. 01/ 160/ 2010 Tentang Rencana Strategi Kementrian Kesehatan Tahun 2010-2014. 2010

4. Direktorat Jendral Perguruan Tinggi. Jumlah Universitas Negeri di Indonesia. Available from: HTTP://www.dikti.go.id. 2006

5. HPEQ-Project. Apa Kata Mahasiswa ? : Partisipasi \& Kolaborasi Mahasiswa Kesehatan Di Indonesia. Jakarta: DiktiKemendikbud. 2011

6. Ma'munah, M. Pengaruh Pendidikan Kesehatan dengan Booklet Terhadap Pengetahuan lbu Laktasi di Wilayah Kerja Puskesmas Ciputat Timur. Skripsi : Fakultas kedokteran dan IImu Kesehatan UIN Syarif Hidayatullah Jakarta : 2015

7. Martina. Hubungan Efikasi Diri dengan Kesiapan Terhadap Interprofessional Education (IPE) Pada Mahasiswa Profesi di FK UGM. 2013

8. Meidiana, R., \& Demsa Simbolon, A. Pengaruh Edukasi melalui Media Audio Visual terhadap Pengetahuan dan Sikap Remaja Overweight. Jurnal Kesehatan Vol. 9 No.3, 478-484. 2018

9. Mulyati, L., \& Mamlukah, M. Model
Pendidikan Interprofesional Dalam Upaya Peningkatan 
Mahasiswa Kesehatan. IImuIImu Kesehatan Bhakti Husada Kuningan, 1- 10. 2017

10. Mursida, N. D., \& Anastasia Suci, D. Pengaruh Media booklet terhadap pengetahuan dan sikap tentang perilaku hidup bersih dan sehat (PHBS) pada siswa di SMP Negeri I Palibelo. 2016

11. Notoatmodjo, S. Promosi Kesehatan Dan Prilaku Kesehatan. Jakarta: PT. Rineka Cipta. 2010

12. Nur'aini. Pengaruh Pendidikan Kesehatan dengan Booklet Terhadap Pengetahuan dan Sikap Menstrual Hygiene Pada Siswi Di SDI Al-Falah I Jakarta. Srikpsi : Fakultas kedokteran dan IImu Kesehatan UIN Syarif Hidayatullah Jakarta :2016

13. Pratiwi, D. A. Efektivitas Pemberian Booklet Terhadap Tingkat Pengetahuan Dan Sikap Pencegahan Hiv dan Aids Pada Remaja Siswa Kelas Viii Dismpn 1 Cangkringan Sleman. 2017
14. Pratiwi, D. R., \& Dea Amarilisia Adespin, B. Faktor Yang Berhubungan Dengan Kinerja Mahasiswa S-1 Pendidikan Dokter Universitas Diponegoro Dalam Pelaksanaan Kegiatan Interprofessional Education Tahun 2017. Jurnal Kedokteran Diponegoro, 667-675.2018

15. Putri, A. T., \& Farit Rezal, A. Efektifitas Media Audio Visual Dan Leaflet Terhadap Peningkatan Pengetahuan, Sikap. JIMKESMAS Vol.2 No.6, 1-11. 2017

16. Susanti, E. Hubungan Tingkat Pengetahuan Dengan Kesiapan Mahasiswa Fakultas Kedokteran Dan IImu Kesehatan Universitas Muhammadiyah Yogyakarta Menghadapi Interprofesional Education (Ipe). Skripsi : Universitas Muhammadiyah Yogyakarta. 2015

17. Susilaningsih, F. S. Praktik Kolaborasi Pada Lingkup Keilmuan Kesehatan. Seminar Pendidikan Interprofesi NHC. Bandung : Universitas Padjajaran. 2014 